O ksana Nadtoka and Vladimir Syromyatnikov

\title{
PHOTOINDUCED SPATIAL ORIENTATIONAL ORDER IN METHACRYLIC THIAZOLE CONTAINING AZOPOLYMERS
}

\author{
Kyiv National Taras Shavchenko University, 64 Volodymyrs'ka str., 01033 Kyiv, Ukraine \\ oksananadtoka@ukr.net
}

Received: October 23, 2007

\begin{abstract}
The new copolymers methyl methacrylate and methacrylic azomonomers containing the tiazole ring in azofragments were synthesized. The combination of the transmission null ellipsometry and total absorption methods have been applied to study $3 \mathrm{D}$ orientational configurations of azochromophores in these polymethacrylates. Under irradiation, if reorientation mechanism of the photoinduced ordering prevails, the azochromophores reorient perpendicularly to the polarization direction of the exciting light $\left(\mathrm{E}_{\mathrm{ex}}\right)$.
\end{abstract}

Keywords: azopolymer, polymethacrylate, photoinduced anisotropy, 3D orientational order

\section{Introduction}

Polymers containing substituted azobenzene groups are being studied as optical storage materials [1]. For "writing" anisotropy can be induced by the orientation of azobenzene groups when exposing a polymer film by a linearly polarized laser.

The mechanism is based on the selective excitation of the azobenzene groups having a dipole component parallel to light polarization. They are undergone a multitude of trans-cis-trans isomerization cycles accompanied by reorientation, thus increasing the concentration of azobenzene groups, perpendicular to the polarization direction. This mechanism involves extensive motion of the side groups and the main chain of the polymer below its glass transition temperature $(T g)$. This mechanism is known as photoreorientation or angular redistribution [2]. When the orientation spot in a polymer film is irradiated by the circularly polarized laser, or heated above $T g$, the anisotropy will be "erased" back to the random state of the unwritten area [3-5].

The optical response of the polymer is mainly influenced by three structural factors: the polymer backbone, the structure of the azochromophore and the linkage between the backbone and the azochromophore. The type of the polymer backbone mostly dictates the mechanical properties, namely the polymer $T g$. The linkage between the azochromophore and the polymer backbone affects both the mechanical properties and the motion of the azogroups, and thus their orientation. The structure of the azochromophore determines such properties as the wavelength of the maximum absorbance, the cis-trans thermal isomerization rate, the orientation ability, as well as the order parameter. In some our previous studies $[6,7]$ it was found that the rate of birefringence achieving and the level of induced birefringence depend on the chemical structure of the azogroups.

While studying the influence of the type and size of azochromophore on orientational properties it was interesting to study such azopolymers which have not only benzene rings but also heterocyclic rings in azochromophore structure. For this aim methacrylic thiazole containing azopolymers were synthesized (Table 1), for all that the thiazole ring was placed in various positions relative to azogroup. Such polymer films were exposed by polarized light to photoinduce the orientation of the chromophore. We used transmission null ellipsometry supported by the modified total absorption method to investigate the $3 \mathrm{D}$ order in these azopolymers. As we earlier proved, this combination is effective and practical tool for the study of the orientational molecular distributions. We consider the induced orientational order as a function of molecular structure, supramolecular organization and irradiation conditions.

To date azopolymers containing heterocyclic rings is not enough investigated and may be of interest as optical reversible storage materials.

\section{Experimental}

\subsection{Materials}

The general structure of azopolymers is shown in Table 1. All chemicals were purchased from commercial suppliers and used without additional purification unless otherwise noted. Standard distillation procedures were applied. The structures of all the precursors and final products were confirmed by ${ }^{1} \mathrm{H}$ NMR spectroscopy. All ${ }^{1} \mathrm{H}$ NMR spectra were taken in $\mathrm{CDCl}_{3}$. The synthesis procedures of all polymers were similar, therefore only the main steps toward making azopolymers are detailed. 


\section{Objects of investigation}

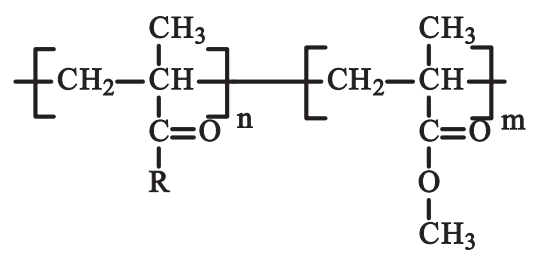

\subsection{Monomer synthesis}

The synthetic route for the target azomonomers (M1 and M2) is shown in Scheme 1. The corresponding monomers were synthesized by general methods. The azocompound $[8,9](0.06 \mathrm{~mol})$ and triethylamine $(9.0 \mathrm{ml})$ were dissolved in THF $(200 \mathrm{ml})$. The solution was cooled in an ice bath for $10 \mathrm{~min}$. A solution of distilled methacryloyl chloride $(6.0 \mathrm{ml}, 0.06 \mathrm{~mol})$ was added slowly to the above mixture. After the addition the mixture was stirred at room temperature for 24 hours. Then the solution was precipitated into distilled water (1 1 ) and the obtained residue was filtered and air-dried. Monomers were recrystallized in ethanol.

2-(4-Methacr yloxyphenylazo)-4-phenylthiazole (M1). Orange crystals; the yield is $69 \%$; melting point (mp) is $411 \mathrm{~K}$ (by DSC). ${ }^{1} \mathrm{H}$ NMR $\left(\mathrm{CDCl}_{3}\right), \mathrm{d}(\mathrm{ppm}): 8.08$ (d, 2H, Ar), 7.40 (d, 2H, Ar), 8.03 (d, 2H, Ar), 7.40 (m, $3 \mathrm{H}, \mathrm{Ar}), 8.15(\mathrm{~s}, 1 \mathrm{H}, \mathrm{Th}), 6.34\left(\mathrm{~s}, 1 \mathrm{H},=\mathrm{CH}_{2}\right), 5.91(\mathrm{~s}$, $\left.1 \mathrm{H},=\mathrm{CH}_{2}\right), 2.05\left(\mathrm{~s}, 3 \mathrm{H},-\mathrm{CH}_{3}\right)$. UV-vis (Ethanol) $\lambda_{\text {max }}: 480$, $530 \mathrm{~nm}$. Elem. Anal. Calculated for $\mathrm{C}_{19} \mathrm{H}_{16} \mathrm{O}_{2} \mathrm{~N}_{3} \mathrm{~S}: \mathrm{C}=65.14 \%$;<smiles>C=C(C)C(=O)Oc1ccc(N=Nc2nc(-c3ccccc3)cs2)cc1</smiles>

Scheme 1. Synthesis of methacrylic azomonomers 
$\mathrm{H}=4.57 \% ; \mathrm{N}=12.03 \% ; \mathrm{S}=9.14 \%$. It was found: $\mathrm{C}=65.15 \%, \mathrm{H}=4.6 \% ; \mathrm{N}=11.93 \% ; \mathrm{S}=9.11 \%$.

$2-\mathrm{M}$ e t h a c r y a m in o- $4-\mathrm{ph}$ e n y $1-5$ phenylazothiazole (M2). Orange crystals; the yield is $56 \%$; mp is $357 \mathrm{~K}$ (by DSC). ${ }^{1} \mathrm{H} \mathrm{NMR}\left(\mathrm{CDCl}_{3}\right), \mathrm{d}(\mathrm{ppm})$ : 12.34 (s, 1H, -NH-), 8,12 (d, 2H, Ar), 7.62 (d, 2H, Ar), $7,32(\mathrm{~m}, 6 \mathrm{H}, \mathrm{Ar}), \quad 6.4\left(\mathrm{~s}, 1 \mathrm{H},=\mathrm{CH}_{2}\right), 5.8\left(\mathrm{~s}, 1 \mathrm{H},=\mathrm{CH}_{2}\right)$, $2.15\left(\mathrm{~s}, 3 \mathrm{H},-\mathrm{CH}_{3}\right)$. UV-vis (Ethanol) $\lambda_{\text {max }}: 400,490 \mathrm{~nm}$. Elem. Anal. Calculated for $\mathrm{C}_{19} \mathrm{H}_{17} \mathrm{ON}_{4} \mathrm{~S}: \mathrm{C}=65.14 \%$, $\mathrm{H}=4.57 \% ; \mathrm{N}=16.09 \% ; \mathrm{S}=9.15 \%$. It was found: $\mathrm{C}=65.13 \%, \quad \mathrm{H}=4.61 \% ; \mathrm{N}=16.11 \% ; \mathrm{S}=9.14 \%$.

\subsection{Polymerization}

Copolymers with methyl methacrylate (MMA) were synthesized by free-radical polymerization in toluene. The polymerization was carried out in $10 \mathrm{wt} \%$ toluene solution of monomer with AIBN as free radical initiator ( $10 \mathrm{wt} \%$ of monomer) at $353 \mathrm{~K}$ for more than 30 hours. Polymers were isolated from the reaction solution by precipitation into excess of methanol followed by reprecipitation from toluene into methanol and then dried at $293 \mathrm{~K}$ for 24 hours. The synthesis is described in more details in a separate paper [10].

The synthesized azopolymers were analyzed by ${ }^{1} \mathrm{H}$ NMR spectroscopy. The obtained results were in agreement with the proposed structures.

The phase transitions were studied by differential scanning calorimetry (DSC) using Perkin Elmer DSC-2 instrument equipped with a IFA GmbH processor at the scan rate of $20 \mathrm{~K} / \mathrm{min}$. The calorimetry calibration was carried out according to well known recommendations [11-13] using sapphire and quartz as standards.

\subsection{Films}

The polymers were dissolved in DMF (2 wt \%) and filtered using $0.2 \mu \mathrm{m}$ Teflon filters. The prepared solution was spin coated on the plates of fused quartz allowing to measure polymer absorption in a UV range. The films were dried at $363 \mathrm{~K}$ for $1 \mathrm{~h}$. Thickness of the films was measured by profilometer. It was varied within $300-1000 \mathrm{~nm}$.

The photo-ordering processes were initiated with a polarized UV light of the high-pressure mercury lamp. The propagation direction of light corresponded to $z$-axis, while polarization of light was always chosen along the $x$-axis of the Cartesian coordinate system with $x$ - and $y$-axis parallel to the verges of the rectangular polymer film and $z$-axis normal to this film. The line of $365 \mathrm{~nm}$ was selected with an interference filter. The light was directed normally to the films. The irradiation was carried out stepwise. After each irradiation step the photoinduced order was evaluated. The time period between irradiation and measurements was about $10 \mathrm{~min}$ to ensure relaxation of cis-isomers (at least their short living fraction).

\subsection{M ethods}

The key method of our studies was the transmission null ellipsometry (TNE). This is a modified version of Senarmont method extended for the measurement of the out-of-plane retardation. The obtained in-plane and outof-plane retardation values $\left(\left(n_{y}-n_{x}\right) d\right.$ and $\left(n_{z}-n_{x}\right) d$, Fig. 1) allowed to conclude about the ellipsoid of refractive index $n_{i j}$ and, finally, about the orientational configuration of azochromophores assuming that directions of maximal values of $n_{i j}$ correspond to the directions of azochromophores maximum location.

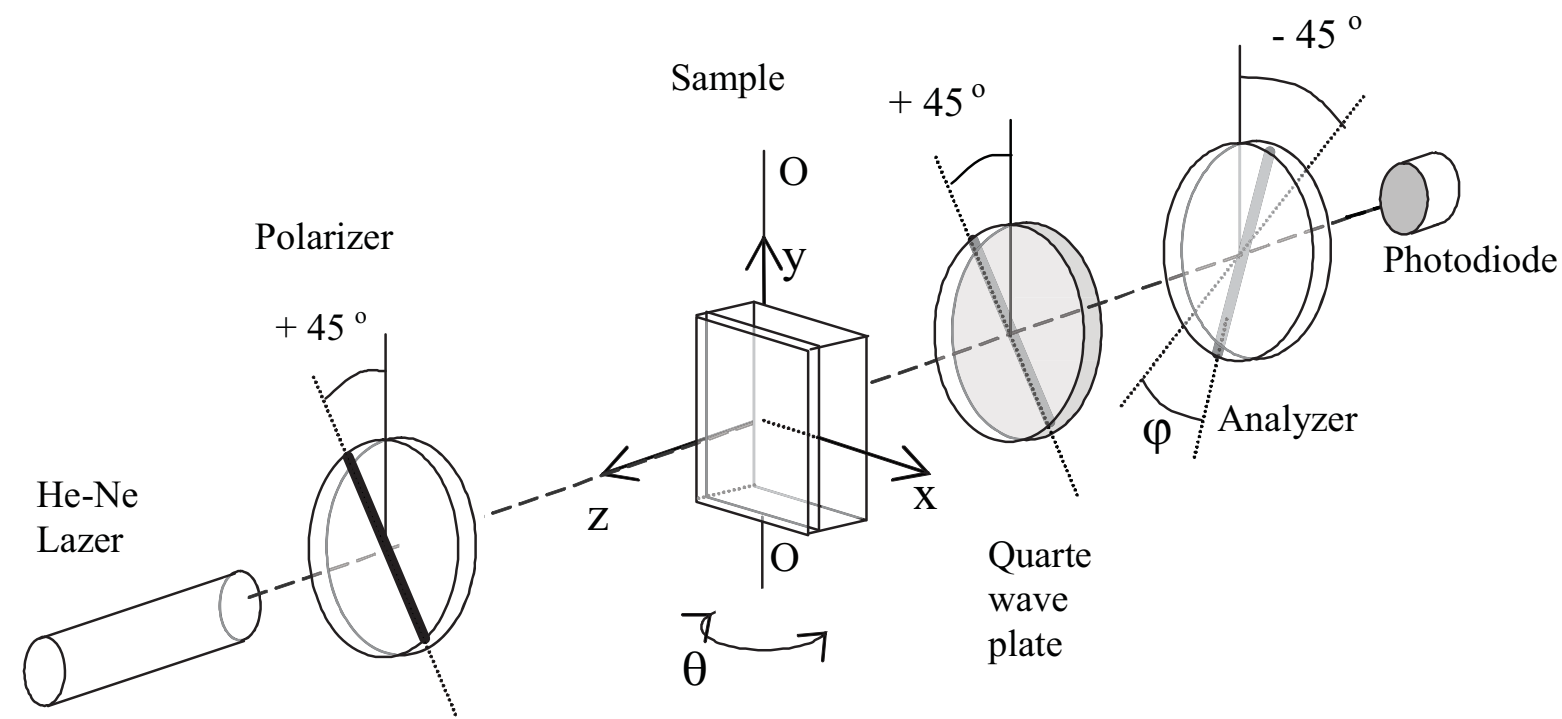

Fig. 1. The in-plane retardation $\left(n_{y}-n_{x}\right) d$ and the out-of-plane retardation $\left(n_{z}-n_{x}\right) d$ obtained as a result of the experimental curves fitting $\varphi(\theta)$ 
As a complementary characterization method, we also have performed 2D dichroism measurement in the $\mathrm{UV} /$ visible spectral range. The $D_{x}$ and $D_{y}$ optical densities, corresponding to $x$ and $y$ in-plane polarizations, are measured with a probe beam propagating perpendicularly to the sample. The third value - out-of-plane component $D$, can be estimated by the total absorption (TA) method, if total absorption $D_{\text {total }}=D_{x}+D_{y}+D_{z}$ is the same for all measuring steps.This is, for instance, true if the photoinduced cis-isomers quickly relax back to a transform and the azochromophores loss is negligible due to a photodegradation. The $D_{\text {total }}$ can be easily obtained, if for a period $t_{0}$ the sample is uniaxial, with an in-plane orientation of the axis of anisotropy, i.e. $y$. Then

$$
\begin{gathered}
D_{\text {total }} \equiv D_{x}\left(t_{0}\right)+D_{y}\left(t_{0}\right)+D_{z}\left(t_{0}\right)= \\
=2 D_{x}\left(t_{0}\right)+D_{y}\left(t_{0}\right)
\end{gathered}
$$

Since we assumed that number of azobenzene units in trans configuration remains constant at each instant of time $t$. $D_{z}(t)$ can be estimated as:

$$
D_{z}(t)=D_{\text {total }}-D_{X}(t)-D_{y}(t)
$$

where $D_{x}(t)$ and $D_{y}(t)$ are experimentally measured inplane components.

Thus, the diagonal terms of the tensor of orientational order $S_{i j}$ can be estimated. For example:

$$
S_{x x}=\frac{D_{x}-\frac{1}{2}\left(D_{y}+D_{z}\right)}{D_{x}+D_{y}+D_{z}}
$$

The components $S_{y y}$ and $S_{z z}$ can be obtained by cyclic permutation in expression (3).

In the original version of TAM, $D_{i}(i=X, y, z)$ corresponds to the maximum of the vibration bands (IR-spectral range) characteristic for azochromophore. In our version the absorption in the UV/Vis range has been measured. We operated with the $D_{i}(i=X, y, z)$ values corresponding to the $\pi \pi^{*}$ absorption maximum of trans-chromophores.

The UV/Vis absorption measurements were carried out using S2000 diode array spectrometer from Ocean Optics Co. The samples were placed normally to the testing light of a deuterium lamp with low intensity. The GlanThomson prism was used to polarize the probe beam.

\section{Results and Discussion}

First of all we measured the UV/Vis absorption spectra of azopolymers (Fig. 2) before and after irradiation with unpolarized UV light (365 nm, normal incidence). These measurements confirm that major photoreaction is trans-cis isomerization revealed itself in strong reducing of $\pi \pi^{*}$ band and increase of $\pi \pi^{*}$ band, which is much more intensive for cis-isomers. The $\lambda_{\pi \pi^{*}}$ values corresponding to maximum of $\pi \pi^{*}$ absorption band are presented in
Table 1. In all polymers, $365 \mathrm{~nm}$ excitation wavelength corresponds to effective adsorption within the $\pi \pi^{*}$ absorption band.

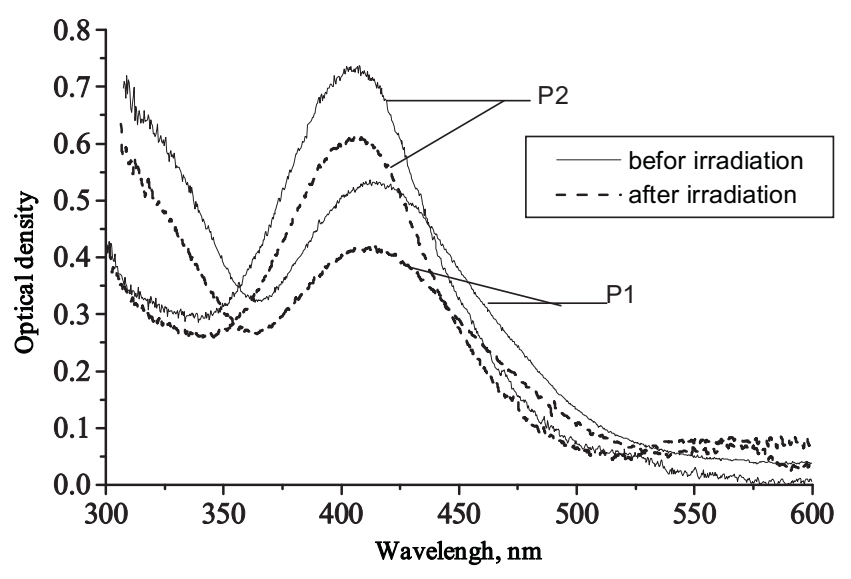

Fig. 2. UV/Vis absorption spectra of P1 and P2 azopolymers before and after irradiation with unpolarized UV light (365 nm, normal incidence).

With regard to results on $3 \mathrm{D}$ ordering, the same type of the ordering behavior can be determined. We describe it using P1 and P2 as examples. The values of the in-plane $\left(n_{y}-n_{x}\right) d$, and the out-of-plane $\left(n_{z}-n_{x}\right) d$ retardation for the $\mathrm{P} 1$ and $\mathrm{P} 2$ films are presented in Fig. 3. The data correspond to successive exposure doses ( $x$ polarization of UV irradiation). The following conclusions can be done. First of all, before irradiation azochromophores demonstrate slight preference to the out-of-plane alignment $\left(n_{z}>n_{x}=n_{y}\right.$, Fig. 3$)$. The irradiation induces identical kinds of transformation of this initial order in two polymers. The same structures are realized in the saturated states of irradiation for two polymers. In polymer films the irradiation results in an oblate order with the $x$ ordering axis $\left(n_{x}<n_{y}=n_{z}\right.$ Fig. 3), the transient orientational structures are biaxial $\left(n_{x} \neq n_{y} \neq n_{z}\right.$, Fig. 3$)$. The $D_{x}$ and $D_{y}$ absorption components as the functions of exposure time measured for P1 and P2 are presented in Fig. 4a and Fig. $4 \mathrm{~b}$ respectively. The behavior of $D_{x}(t)$ and $D_{y}(t)$ curves in Fig. 4a and Fig. 4b is typical for reorientation mechanism: increase of $D_{y}(t)$ and simultaneous decrease of $D_{x}(t)\left(x|| \mathrm{E}_{\mathrm{ex}}\right)$ is an evidence of redistribution of azochromophores with the increase of their concentration in the $y$ direction perpendicular to the light polarization $\mathrm{E}_{\mathrm{ex}}$

As it was shown in previous works $[3,14]$ the reorientation mechanism may be an evidence of short lifetime of cis-isomers. If it is really so, the total absorption of $D_{\text {total }}$ azochromophores can be constant practically after every irradiation steps. In conjunction with the fact of the uniaxial ordering in a steady state $\left(n_{y}=n_{z}\right)$ we may apply TA method to calculate $D_{z}$ component. 


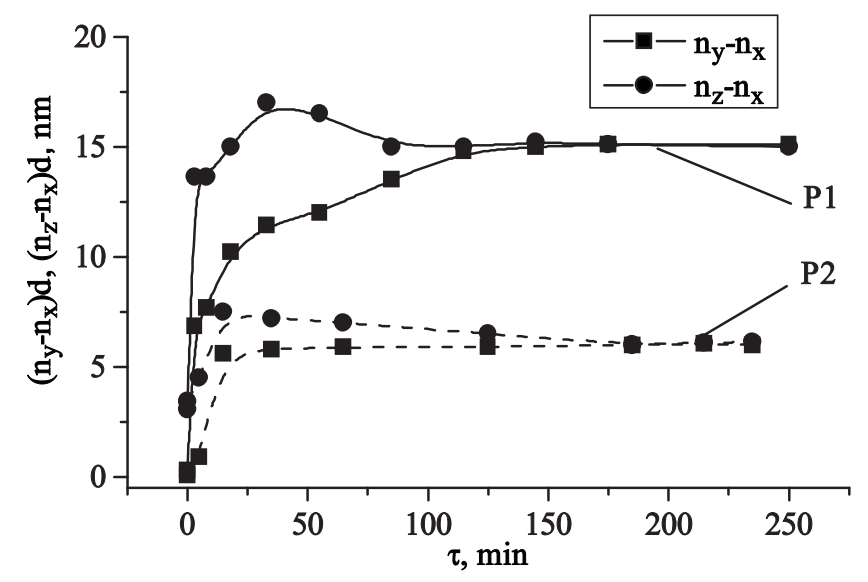

Fig. 3. The kinetics of phase retardation components $\left(n_{y}-n_{X}\right) d$ and $\left(n_{z}-n_{X}\right) d$ for successive irradiation doses for P1 and P2 polymers. Light irradiation with $\lambda_{\text {ex }}=365 \mathrm{~nm}$ ( $\mathrm{I}=5 \mathrm{~mW} / \mathrm{cm}^{2}$, x polarization $)$.
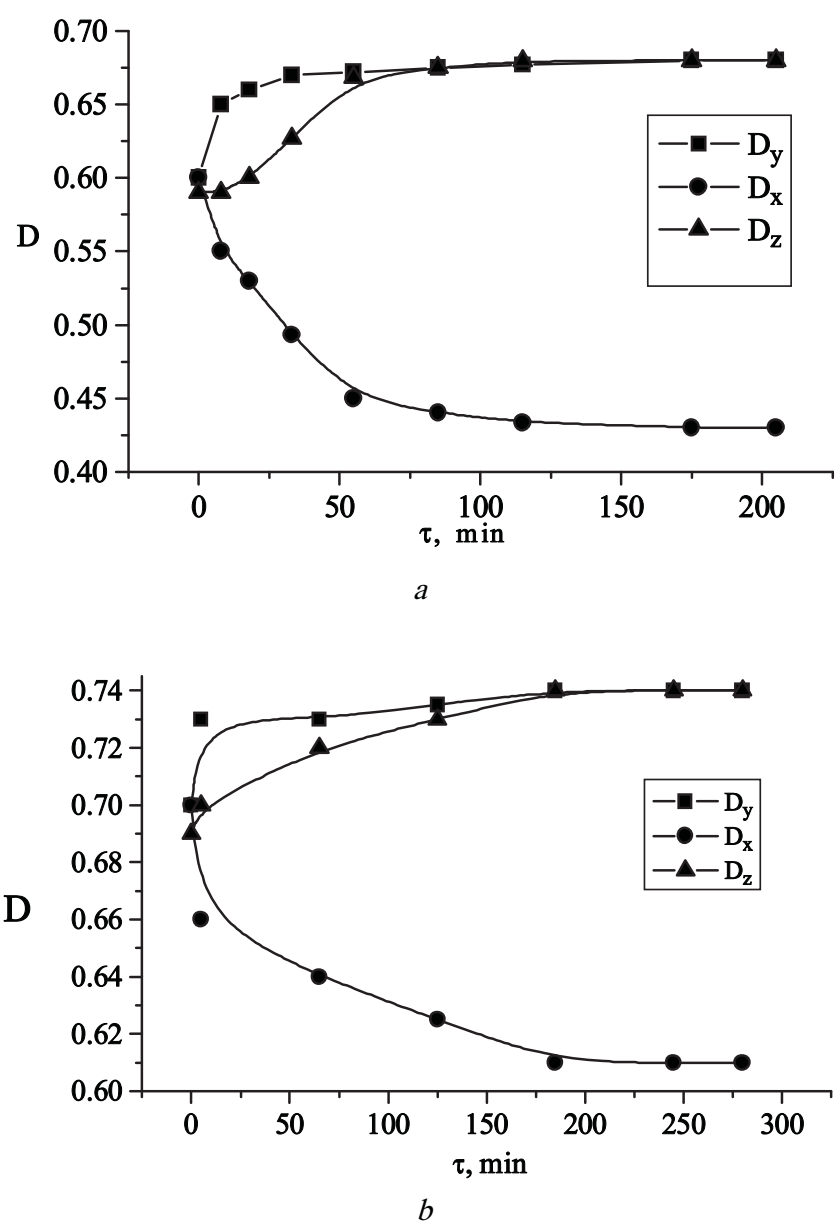

Fig. 4. The kinetics of the $D, D$ and $D$ absorption components for successive espouse doses for P1 (a) and P2 (b) polymers. Light irradiation with $\lambda_{\mathrm{ex}}=365 \mathrm{~nm}$ (I $=5 \mathrm{~mW} / \mathrm{cm}^{2}$, x polarization).
The $D_{i}(i=X, y, z)$ values were used to calculate the diagonal components $S_{x,} S_{v y}$ and $S_{z z}$ of the order parameter tensor $\hat{S}$ according to (3). The uniaxial oblate distribution of azochromophores with the $x$ ordering axis, realized in the steady state of irradiation, is characterized by the scalar $S \equiv S_{\mathrm{xx}}=-0.14$ for P1 and $S \equiv S_{\mathrm{xx}}=-0.06$ for P2. The initial order of azochromophores (uniaxial ordering along the film normal) is also characterized by scalar: $S \equiv S_{\text {z }}=0.07$ for P1 and $S=S_{z z}=0.03$ for P2. The latter value indicates that initial out-of-plane ordering is rather weak. The transient structures between the uniaxial structures in the initial and steady state of excitation are biaxial and so can be described at least with three (diagonal) elements of $\hat{S}$. Qualitatively, the general tendency of the 3D order transformation under irradiation for tiazole containing azopolymers does not depend on heterocycle place in azochromophore. Copolymers containing heterocyclic ring in azofragment structure have anisotropic properties under polarized light. At the same time the orientational mechanism and the final photoinduced alignment of the azochromophores are similar to the azobenzene fragments with acceptor substitutes [7]. The general tendency of the photoinduced ordering allows to conclude that in the azopolymers the photoinduced order is mainly determined by the molecular photoordering through reorientation mechanism.

Nevertheless the above mentioned molecular variations influence the induced birefringence and dichroism, which in their turn determine ordering rate of azochromophores. These quantitative regularities are shown in Table 2.

Table 2

Order parameter tensor $S=S_{\mathrm{xx}}$, birefringence $(\Delta \mathrm{n})$ and azochromofores ordering time $(\tau)$ for P1 and P2

The change of azofragment structure by the replacement of benzene ring with thiazole ring having two heteroatoms decreases birefringence $(\Delta \mathrm{n})$ and needs more time for azochromofores ordering $(\tau)$ in P2. This effect may be explained by heteroatoms ability for the formation of hydrogen bonds [15]. However, the copolymer with azofragment containing tiazole ring far from main chain (P1), demonstrates good ability to photoinduced ordering and possesses effective anisotropic properties under the polarized UV-light. It is known, that tiazole-contaning azochromofores have photodestruction good stability [16] and often are characterized with long-wave maximum of absorption. These properties are supplemented by ability to photoinduced ordering and allow us to propose polymers containing azotiazole backbone chains as materials for reversible optical storage. 


\section{Conclusions}

Thus, studying the 3D orientational ordering in the tiazole-containing azopolymethacrylates we have determined the regularities earlier established for the other kinds of azopolymers [6], as well as polymers containing cinnamoyl photosensitive groups [17]. The main rule says that under photoexcitation the initial orientational distribution (often, uniaxially ordered due to the self-ordering of photosensitive groups) is transformed into some other uniaxially ordered distribution in case of photoreorientation mechanism. The transient structures between the initial and the final uniaxial distributions are biaxial. Before irradiation, the azochromophores in the studied polymers demonstrate preference to the out-of-plate alignment that can be caused by the self-ordering in the diluted polymers under the film formation. The final photoinduced alignment is a result of photoorientation. The observed regularities were earlier described for several other classes of photosensitive polymers and so they may be common rules for photoordering in the photochromic media.

Obtained results indicate also the influence of the azochromophore structure on the appearance, intensity and kinetic parameters of the photoinduced anisotropy such as photoinduced birefringence and orientational ordering in polymers.

\section{Acknowledgments}

The authors are greatly indebted to Yaroshchuk O. from the Institute of Physics (NASU) for a rendering a technical opportunity for physical researching.

\section{References}

[1] Ichimura K., Seki T., Kawanishi Y., Suzuki M.S., Sakuragi M. and Tamaki T.: [in:] Photoreactive Materials for UltrahighDensity Optical Memory. Elsevier, Amsterdam 1996.

[2] Dumont M.: Mol. Cryst. Liq. Cryst., 1996, 282, 437.

[3] Todorov T., Nikolova N. and Tomova N.: Appl. Opt., 1984, 23, 4309.

[4] Ho M., Natansonh A. and Rochon P.: Macromolecules, $1995,28,6124$
[5] Lascker L., Fisher Th., Stumpe J., Kstromin S., Ivanov S., Shibaev V. and Ruthmann R.: Mol. Cryst. Liq. Cryst., 1994, 246, 347.

[6] Yaroshchuk O., Dumont M., Zakrevskyy Yu., Bidna T. and Lindau J.J.: Phys. Chem. B., 2004, 108, 4647.

[7] Nadtoka O., Syromyatnikov V., Olkhovik L., Yaroshchuk O. and Bidna T.: Mol.Cryst.Liq.Cryst., 2007, 468, 63.

[8] Sami Sh. A. and Osman A.A.: Heterocycl. Chem., 1976, 13, 45.

[9] Srivastava P.K., Upadhyuva I.S. and Sharma R.P.: J. Chem. and Eng. Data, 1976, 21, 508.

[10] Nadtoka O., Syromyatnikov V. and Olkhovykh L.: Mol. Cryst. Liq. Cryst., 2005, 427, 259.

[11] Wunderlich B. Boller A., Okazaki I. and Ishikiriyama K.: Thermochim. Acta, 1997, 304/305, 125.

[12] Ribeiro M. and Grolier J.-P.: J. Thermal Anal. \& Calorimetry, 1999, 57, 253.

[13] Wunderlich B.: Prog. Polymer Sci., 2003, 28, 383.

[14] Dumont M. and Sekkat Z.: Proc SPIE, 1992, 188, 1774.

[15] Stepanov B.I.: Vvedenie v khimiju i tehnologiju organicheskih krasitelej. Khimija, Moskva 1971.

[16] Savransky L., Klimenko O., Syromyatnikov V. and Fedorova L., Functional Materials, 1998, 5, 380

[17] Yaroshchuk, O., Sergan T., Kelly J. and Gerus I.: Jpn. J. Appl. Phys., 2002, 41 (1), 275.

\section{ФОТОІНДУКОВАНА ПРОСТОРОВА ОРІЕНТАЦІЙНА ВПОРЯДКОВАНІСТЬ У МЕТАКРИЛОВИХ ТІАЗОЛВМІСНИХ АЗОПОЛІМЕРАХ}

Анотація. Було синтезовано нові кополімери метилметакрилату та метакрилових азомономерів, що містять тіазольне кільие в азофрагментах. Поєднання методу пропускної нуль-еліпсометрії та методу поглинання було використано для вивчення тривимірної орієнтаційної конфігурачії азохромофорів в цих поліметакрилатах. При опроміненні, у разі реалізації механізму переорієнтації азохромофори орієнтуються перпендикулярно до напрямку поляризацї світла, щуо падає $\left(\boldsymbol{E}_{e x}\right)$.

Ключові слова: азополімер, поліметакрилат, фотоіндукована анізотропія, $3 D$ орієнтаційна впорядкованість 